\title{
An Analysis of Questionnaire Survey on Online Evaluation of Teaching by University Undergraduates
}

\author{
Dongyun Sun $^{1}$ \\ ${ }^{1}$ Changchun University of Science and Technology, Changchun, China \\ Correspondence: Dongyun Sun, Changchun University of Science and Technology, Changchun 130022, Jilin, \\ China. E-mail: sundongyun@cust.edu.cn
}

\author{
Received: October 14, 2013 Accepted: November 1, 2013 Online Published: November 22, 2013 \\ doi:10.5539/hes.v3n6p58 \\ URL: http://dx.doi.org/10.5539/hes.v3n6p58
}

\begin{abstract}
This paper takes into consideration of the problems discovered in the teaching evaluation data statistics over the years in Changchun University of Science and Technology and cooperates with related departments to conduct a questionnaire survey on an online evaluation of teaching, with the purpose of detecting cognition of students in evaluation of teaching at present, the effect and problems existing, facilitate and improve online evaluation of teaching and enhance education and teaching quality in the university.
\end{abstract}

Keywords: education, teaching, online evaluation of teaching, teaching quality

\section{The Cause for Implementation of Online Evaluation of Teaching and Issues to Study}

\subsection{The Cause for Implementation of Online Evaluation of Teaching}

It has become a routine means to conduct evaluation on teaching by students that undergraduates make an online evaluation of teaching through the module of evaluation of teaching within the educational management system. Ever since 2007 when Changchun University of Science and Technology conducted evaluation on undergraduate education and teaching level organized by the Ministry of Education, online evaluation of teaching has gone through six springs and autumns. During this period, the online teaching evaluation system has been continuously improved and the indicator of evaluation of teaching has been modified. In order to have better understanding in the specific operation and thinking mode of students in the process of evaluation of teaching, we make a sampling survey on online evaluation of teaching by undergraduates in this university and finally provide reference for improving the education and teaching quality in the university.

Ever since online evaluation of teaching was carried out in Changchun University of Science and Technology, we have conducted detailed statistics on the evaluation result at the end of each semester, namely, the comprehensive performance of teachers. The result shows such a problem that the comprehensive performance of teachers has been improved year by year in a stepped way. The situation has changed from the fact that the comprehensive performance of teachers are not qualified at the very beginning to the fact that the comprehensive performance of teachers is almost above 95 scores at present. Is it really that the teaching level of teachers in the university has been all improved or are there some other reasons? Keeping such a doubt in mind, we respectively hold several teacher and student symposiums and come to such a conclusion from teaching supervision experts who attend a lecture that, indeed, the teaching level of teachers has been improving year by year. However, some individual teachers also have certain problems in terms of teaching mode and teaching method and fail to achieve the result of excellence in their course performance. Based on that, after approval of leaders in the university, the office of teaching affairs take detailed responsibility for a questionnaire survey on online evaluation of teaching by undergraduates to a large extent.

\subsection{Issues to Study}

The issues to study contain understanding in students" cognition in "online evaluation of teaching" and finding out unfavorable factors existing in the evaluation teaching of students. The survey content is mainly to know about the implementation situation of students' evaluation activities through the psychology and attitude of students' participation in evaluation of teaching. The aim is to find out the extant problems and the potential reasons. This questionnaire survey is mainly conducted for the following problems: meaning of evaluation of teaching, content of evaluation of teaching, influencing factors and existing problems. The significance of the 
survey is to better improve the undergraduate education and teaching quality of the university, give full play to the subject role of students, further enhance the teaching and evaluation of teaching system and facilitate improvement of teaching management level.

\section{Method of Survey and Study}

After agreement of the leaders in charge, the problems of study in the questionnaire survey are established. We look up a lot of relative data in the network. And after consultation with teachers from the department of social work in the college of law, we finally formulate a "survey questionnaire about online evaluation of teaching by undergraduates". This questionnaire mainly studies reliability of evaluation of teaching, influencing factors, arrangement of evaluation time and evaluation system. The method adopted is that students whose student number ends up with five in each class at each grade fill in the survey questionnaire. Altogether, 677 questionnaires are sent out and 643 questionnaires are recovered. The recovery rate is $94.9 \%$ and 616 questionnaires are effective. The survey respondents are undergraduates who enter the school respectively in the year 2009, 2010, 2011 and 2012.

\section{Conclusion of the Questionnaire Survey}

Through the survey, we come to find out the following four points. Firstly, a large majority of students hold an objective and fair attitude in the evaluation of teaching and students' evaluation on teaching of teachers is of certain reference for assessment on their performance. Secondly, humor, respect towards students, fairness, kindness and a large stock of knowledge are the most important factors in influencing students' evaluation of teaching. Thirdly, inappropriate arrangement of the time for evaluation of teaching affects the objectivity and fairness of the result of the evaluation. Fourthly, the evaluation system of teachers is not scientific enough and this affects the objectivity and comprehensiveness of the result of the evaluation.

\subsection{The Situation of Students Participation in the Evaluation of Teaching}

Table 1. Whether students personally participate in the activity of evaluation of teaching each time

\begin{tabular}{ccccc}
\hline & Frequency & Percentage & Effective percentage & Accumulative percentage \\
\hline Yes & 565 & $91.7 \%$ & $92.3 \%$ & $92.3 \%$ \\
No & 46 & $7.5 \%$ & $7.5 \%$ & $99.8 \%$ \\
Absent & 1 & $0.2 \%$ & $0.2 \%$ & $100.0 \%$ \\
Total & 612 & $99.4 \%$ & $100 \%$ & \\
Value of absense & 4 & $0.6 \%$ & & \\
Total & 616 & $100.0 \%$ & & \\
\hline
\end{tabular}

From Table 1, it can be found that among the 612 students who are within the scope of the statistics, there are 562 students who personally participate in the activity of the evaluation, which accounts for $91.7 \%$ of the total. And there are 46 students who do not personally participate in the evaluation of teaching and who find somebody else to take their position, which accounts for $7.5 \%$ of the total.

\subsection{Opinions on Evaluation of Teaching}

Table 2. Opinions on the activity of evaluation of teaching

\begin{tabular}{lccc}
\hline Opinions on the activity of the evaluation & Frequency & Percentage & Ratio of samples \\
\hline Help to know about the situation of teaching & 320 & $27.5 \%$ & $52.6 \%$ \\
Improve the teaching level & 328 & $28.2 \%$ & $53.9 \%$ \\
Help for democratic management & 147 & $12.6 \%$ & $24.2 \%$ \\
Important evidence for evaluation of the & 207 & $17.8 \%$ & $34.0 \%$ \\
teaching level & & & \\
Without much significance & 163 & $14.0 \%$ & $26.8 \%$ \\
Total & 1165 & $100.0 \%$ & $191.6 \%$ \\
\hline
\end{tabular}


From Table 2, it can be found that students who believe evaluation of teaching can help teachers to know about the situation of teaching account for $27.5 \%$ of the total, students who think evaluation of teaching is helpful for the democratic management of students account for $12.6 \%$ of the total, students who think that evaluation of teaching is an important evidence to evaluate the teaching level of teachers account for $17.8 \%$ of the total and students who believe evaluation of teaching is without much significance account for $14 \%$ of the total. This indicates that a large part of students still hold a positive attitude towards online evaluation of teaching and think that it can improve the teaching level of teachers. Nevertheless, there are still a large proportion of students who hold an indifferent attitude towards online evaluation of teaching. Thus, the school needs to do a lot of work in terms of publicity.

\subsection{Reasons for Giving a High Score to Teachers in the Evaluation of Teaching}

Table 3. The major reasons for giving a high score to teachers in the evaluation of teaching

\begin{tabular}{lccc}
\hline Major reasons & Frequency of the sample & Percentage & Ratio of sample \\
\hline $\begin{array}{l}\text { Teaching is precise and } \\
\text { is in good order }\end{array}$ & 331 & $37.7 \%$ & $54.5 \%$ \\
$\begin{array}{l}\text { Teaching is humorous } \\
\text { and funny }\end{array}$ & 262 & $29.8 \%$ & $43.2 \%$ \\
$\begin{array}{l}\text { Strict requirement for } \\
\text { students }\end{array}$ & 24 & $2.7 \%$ & $4.0 \%$ \\
$\begin{array}{l}\text { Good relationship with } \\
\text { students }\end{array}$ & 116 & $13.2 \%$ & $19.1 \%$ \\
$\begin{array}{l}\text { Wish to have a high } \\
\text { score in the exam }\end{array}$ & 102 & $11.6 \%$ & $16.8 \%$ \\
Other reasons & 44 & $5.0 \%$ & $7.2 \%$ \\
Total & 879 & $100.0 \%$ & $144.8 \%$ \\
\hline
\end{tabular}

From Table 3, it can be found that, over half of students make evaluation on teachers for the major reasons that their teaching is precise and is in good order and that their teaching is humorous and funny. This proves that evaluation of students on teachers is based on rationality. In addition, there are approximately a quarter of students who make biased evaluation on teachers.

3.4 Factors that Affect the Evaluation of Teaching

Table 4. Factors that affect your objective evaluation in giving a score to teachers

\begin{tabular}{lccc}
\hline Objective evaluation factors & Frequency & Percentage & Ratio of sample \\
\hline $\begin{array}{l}\text { Degree of favor for teachers } \\
\begin{array}{l}\text { Impression on teachers } \\
\text { during the period of } \\
\text { evaluation }\end{array}\end{array}$ & 355 & $37.2 \%$ & $58.9 \%$ \\
$\begin{array}{l}\text { Traits of teachers in a } \\
\text { certain aspect }\end{array}$ & 206 & $21.6 \%$ & $34.2 \%$ \\
$\begin{array}{l}\text { Evaluation of teaching } \\
\text { follows suits }\end{array}$ & 133 & $27.3 \%$ & $43.3 \%$ \\
Total & 955 & $13.9 \%$ & $22.1 \%$ \\
\hline
\end{tabular}

From Table 4, it can be found that the score given by students to performance of teachers mainly depends on the degree of favor for teachers. However, whether a teacher has traits in a certain aspect is able to attract students and the impression of students on teachers during the period of evaluation of teaching only have inferior influences upon the performance of teachers in the evaluation of teaching. 


\subsection{Standard of Evaluation on Teachers' Teaching Quality}

From our survey, it is seen that in evaluation of students on the education quality of teachers, the teaching attitude of teachers accounts for $36.04 \%$, the teaching method and means of teachers accounts for $25.49 \%$, the teaching effect of teachers accounts for $22.89 \%$ and the professional work and professional level of teachers account for $15.42 \%$. Subjectively speaking, in the evaluation of students on the education quality of teachers, students' mastery of the knowledge they learn accounts for $41.56 \%$, students' capacity of application in the knowledge they learn accounts for $36.20 \%$, students' favor for teachers accounts for $12.34 \%$ and students' favor for a subject accounts for $9.90 \%$.

\subsection{Phenomenon Existing among the Group of Teachers in the Process of Evaluation of Teaching}

Table 5. Bad condition among the group of teachers in the process of evaluation of teaching

\begin{tabular}{lccc}
\hline Bad condition among the group of teachers & Frequency & Percentage & $\begin{array}{c}\text { Ratio of } \\
\text { sample }\end{array}$ \\
\hline $\begin{array}{l}\text { Teachers discuss evaluation of teaching in the classroom } \\
\text { and give a hint to students to give them a high score }\end{array}$ & 114 & $14.3 \%$ & $19.0 \%$ \\
$\begin{array}{l}\text { Teachers spare no expense to ingratiate themselves with } \\
\text { students in relaxing the requirements for a class in order to } \\
\text { get a high score }\end{array}$ & 79 & $9.9 \%$ & $13.1 \%$ \\
$\begin{array}{l}\text { Teachers do not make any change in the behavior of } \\
\text { teaching as for the result of the evaluation of teaching }\end{array}$ & 337 & $42.2 \%$ & $56.1 \%$ \\
$\begin{array}{l}\text { Teachers distinguish their scoring on students at the end of } \\
\text { a semester based on students' evaluation on them }\end{array}$ & 123 & $15.4 \%$ & $20.5 \%$ \\
$\begin{array}{l}\text { Others } \\
\text { Total }\end{array}$ & 146 & $18.3 \%$ & $24.3 \%$ \\
\hline
\end{tabular}

From Table 5, it can be found that, first of all, teachers do not have correct cognition in the evaluation of teaching. Some teachers in the classroom even induce students to give them a high score in the classroom. In order to get a high score, teachers even spare no expense to ingratiate themselves with students in relaxing the requirements for a class and distinguish their scoring on students at the end of a semester based on students' evaluation on them. These behaviors, invisibly, distort the actual significance of evaluation of teaching.

\section{An Analysis of the Conclusion of the Questionnaire Survey}

\subsection{An Analysis of the Reliability Result of the Evaluation of Teaching}

At present, university students are relatively mature in all aspects. They are good at thinking in a rational way with a high sense of responsibility and are able to take responsibility for their own behaviors. Thus, the result of evaluation of teaching has high reliability. Nevertheless, on the other hand, as a result of several subjective and objective factors, such as internship and arrangement of the time of evaluation, the objectivity and fairness of the evaluation is reduced and the phenomenon of scoring at random appears.

\subsection{An Analysis of the Result of the Influencing Factors}

As the subject of teaching, students have strong sense of selfness. In addition, young students are full of vigor and vitality, with strong sense of thirst for knowledge and like to explore new thinks. Such a series of factors make students like teachers who are humorous, show respect for students, fairness, kindness and who have a large stock of information. However, the gender and age of teachers have no great influence. This is of great enlightenment significance to teaching of teachers.

\subsection{An Analysis of the Result of the Evaluation System}

Nowadays, setting of undergraduate courses is not only complex but also broad, and design of the questionnaire about evaluation on teachers only involves such external factors as the teaching attitude and teaching content of teachers and fails to go deep into the core problem of courses. The indicator system of students' evaluation of teaching should not be formulated randomly. The randomness of evaluation of all work in the universities from the indicator system of ranking list to school running level is large and formulation of the indicator system 
usually is based on experience. For example, the office of teaching affairs usually adopts a set of evaluation program that copies foreign evaluation institution. As a result of "endemic", the evaluation program fails to take into consideration of the actual problems of the university and evaluation of students is just like "chicken ribs", which greatly weakens enthusiasm of evaluation and is not favorable for stabilizing the reliability of students' evaluation of teaching. Only scientific and rational indicators can correctly judge and evaluate the teaching quality of the class. Establishment of a rational classroom teaching quality evaluation system should take into full consideration of the characteristics of the university according to modern education and teaching theory, features of contemporary classroom teaching and basic requirements for classroom teaching of teachers. Since the classroom teaching has various forms, and teachers adopts different types of teaching modes according to the features of students, the course content, teaching conditions and knowledge preparation of themselves, they should design different evaluation indicator systems according to different courses and different teaching forms and give full play to the role of students in evaluation of teaching.

\subsection{An Analysis of the Result of the Survey on the Time of Evaluation of Teaching}

As the evaluation of teaching is arranged prior to selection of a course, students are reluctant to spend too much time in evaluation of teaching in order not to delay their selection of the course. This results in the hastiness to give a score and the phenomenon of scoring at random is relatively general. Besides, during the period of the selection of a course, fluctuation of students' emotion, such as, anxiety, may also affect the objectivity and fairness of evaluation of teaching.

\section{Research Conclusion and Policy}

\subsection{Give Full Play to the Subjective Role of Students in Evaluation of Teaching}

First of all, the university should guide students in their evaluation. Just as the survey indicates, the evaluation attitude of students is one of the most important factors in influencing the evaluation quality of students. Evaluation attitude is mainly an issue of cognition. Therefore, it is necessary to take multiple measures to improve cognition of students in evaluation of teaching. The university can publicize through multiple approaches, such as, system, document, learning manual, broadcast, school newspaper and conference, to enhance students' cognition of evaluation purpose and significance and stimulate students' consciousness of right and responsibility.

Then, it is necessary to help students form necessary evaluation capacity. Evaluation of teaching by students is a job that calls for speciality and its requirement for evaluators is reflected in its requirement for the evaluation capacity of students. Evaluation capacity is to ensure that students can see the essence of a thing from complicated phenomena. Training and learning is an effective approach to improve the evaluation capacity of students and to promote the professionalization of students' evaluation of teaching. Forms of training and learning are also various and we can start from the following several aspects. Firstly, it is to open special lectures on higher pedagogy and evaluation in universities so as to enable students to know about knowledge in evaluation. Secondly, it is to give concentrative lectures regarding the purpose, significance, standard, procedure and norm of evaluation prior to test of evaluation. Thirdly, it is to conduct discussion on students' evaluation within the university, which involves the purpose, significance, evaluation standard, evaluation method and advantages and disadvantages of evaluation to promote students to think about problems regarding their evaluation of teaching and enable them to learn in the process of discussion and improve themselves in discussion.

\subsection{Teachers Need to Improve Themselves Continuously in Terms of Teaching Method and Conducting Themselves in the Society}

As university teachers, profound knowledge is easy to learn, but the teaching method adopted by them is not easy to satisfy their students. The teaching method of teachers is not flexible and diverse enough and the teaching means is not appropriate and effective enough, so teachers are lacking in effective methods in stimulating students' thinking and innovation. As a result, the teaching seems boring and is deficient of attraction. Therefore, in order to improve the teaching effect, teachers have to have full enthusiasm and bring humor to the class to strengthen interaction between teachers and students and let the class become magnificent and vivid. In the meantime, another important aspect is that the attitude of teachers in conducting themselves also affects students. Since every word and action of teachers affects students, we can also know from the survey that students attach great importance to the personality magic of teachers. Kindness, respect towards students and fairness and justice of teachers are personality of teachers who are most welcome. Thus, at the time when teachers do a good job in teaching, they should also pay attention to improvement of their own moral quality. 


\subsection{Make the Evaluation Procedure Strict}

The evaluation procedure stipulates the working procedure and specific implementation rules which the evaluation process has to carry out and which are the system assurance for objectivity and justice of the evaluation. Strict evaluation procedure should have the force of constraint on both evaluators and those who are evaluated. Both of them are supposed to carry out evaluation according to strict evaluation procedures. This helps to reduce random error and system error in the process of evaluation and enhance reliability and validity of the evaluation result.

\subsection{Design Scientific and Rational Evaluation Indicators}

The basic components of evaluation of students should at least include the four aspects of teaching content, teaching method, teaching attitude and teaching effect, which are integral. Among the four components, teaching content is the fundamental one of classroom teaching, teaching method is the approach to convey teaching content to students, teaching attitude is the effective assurance for teaching effect and teaching effect is the result of the first three factors' combined effect on students. It involves the three aspects of the system of classroom teaching. Teaching content and teaching attitude are the input part, teaching method is the process implementation part and teaching effect is the result output part. Through output of the result, teachers get feedback to further adjust and improve teaching content and method, which forms a loop-locked system.

The university should let students participate in design of the evaluation indicators and make the evaluation indicators recognized by the teachers. The teaching quality of teachers is finally reflected by the learning effect of students. Students have most profound experience about what kind of teachers is best. Therefore, students' participation in design of the indicators for evaluation of teachers' teaching quality highlights students' subjective role in the process of teaching. This objectively mobilizes students' enthusiasm and initiative in participating in teachers' teaching quality evaluation activity and promotes them to participate in this job with a careful and responsible attitude, which ensures impartiality of the evaluation result. Meanwhile, the evaluation indicators should get recognition from teachers, because only if the evaluation result is persuasive to teachers, can the actual purpose of evaluation be achieved.

\subsection{Set up Rational Evaluation Time}

The teaching management institute ought to take full consideration of students' actual situation and make rational arrangement on the time of evaluation so as to provide guarantee for students' evaluation of teaching. For instance, the institute may make evaluation two months after a new semester starts. This not only guarantees in terms of time, but also ensures that students already have a comprehensive understanding in teachers after two months of learning so as to be helpful to ensure the impartiality and justice of the evaluation of teaching.

\subsection{Make Scientific Statistics on the Result of Evaluation}

We ought to hold a scientific attitude and precise style to treat with each aspect in the process of evaluation. For example, before the evaluation, we should provide evaluation training on students in due course so as to ensure the justice and scientificness of the evaluation. When we deal with the evaluation result, we should employ precise statistical technology and get rid of interference from human factors to ensure the authenticity of the data. When we use the evaluation result, we should strengthen the feedback effect, which can not only provide simple results, but also needs to provide opinions for improvement.

In one word, through an analysis in the "questionnaire of survey on online evaluation of teaching by university students", we come to know about the status quo of online evaluation of teaching in the university and problems existing. The university is supposed to take certain measures in the future to further improve the teaching evaluation system, strengthen management of teaching and enhance the education quality of undergraduate in the future.

\section{References}

Cai, M., \& Zhang, L. (2005). Study of Survey on University Students' Participation in Evaluation of Teachers' Teaching. Journal of Higher Education, 2005(3).

Fu, L.-Y. (2009). Problems and Strategies of Evaluation on the Internet by College Students. Journal of Architectural Education in Institutions of Higher Learning.

Meng, F. (2010). Study on the Evaluation of Teaching System among University Students from a Perspective of Stakeholders. Huazhong University of Science and Technology.

Zhao, Q.-L., Wang, N.-N., \& Sun, Y. (2010). Investigation on College Students' Evaluation on Internet. China Higher Medical Education. 


\section{Copyrights}

Copyright for this article is retained by the author(s), with first publication rights granted to the journal.

This is an open-access article distributed under the terms and conditions of the Creative Commons Attribution license (http://creativecommons.org/licenses/by/3.0/). 